\title{
Tightening the Grip over an Elusive System: Innovative Practices
}

\author{
Abdul Latheef Vennakkadan ${ }^{1} \&$ Julius Irudayasamy $^{1}$ \\ ${ }^{1}$ Foundation Program, Dhofar University, Oman \\ Correspondence: Abdul Latheef Vennakkadan, English Instructor, Foundation Program, Dhofar University, PO \\ Box No. 2509, Salalah-211, Oman. Tel: 968-9827-4684. E-mail: latheefv@gmail.com
}

\author{
Received: May 17, 2014 Accepted: June 17, 2014 Online Published: July 15, 2014 \\ doi:10.5539/elt.v7n8p116 URL: http://dx.doi.org/10.5539/elt.v7n8p116
}

\begin{abstract}
The present study examines the need for a specific approach to spelling instruction in ELT curriculum for ESL/EFL learners as it is an area where the L2 learners encounter a lot of learning difficulties or experience both inter/intra linguistic transfer. The study further explores the rationale for combating the spelling difficulties of ESL/EFL learners and the possibilities of integrating innovative practices that the writer successfully experimented with while trying to help his English students gain a grip and grasp of the elusive English orthography. The real plus of these practices is that they can be applied across learner levels and background and it expects the teacher to take a back seat in spelling instruction. These improvised tactics, though more for the sake of an abbreviation than a terminology are called the Learner Forefront Approach (LFA). LFA is a creative blend of the traditional as well as multisensory approaches to spelling because it makes use of the students' digital literacy, schematic knowledge, first language (L1), analytical thinking and certain strikingly improvised memory tactics to enable them to associate the problems areas (PAs) of words with their prior knowledge. The salient feature of this method lies in making the whole learning process edutaining as well as learner-centered.
\end{abstract}

Keywords: English orthography, learner forefront approach, problem area, picturisation, e-resources

\section{Introduction}

Teaching or learning spelling continues to be a point of serious concern even after much research has been there across the globe in the field of methodology or material in teaching English as a second/foreign language. It is noted (Fender, 2008) that the lack of proper development of spelling knowledge not only affects ESL learners' word recognition abilities in English but also negatively affects the proper development of their reading skills from the very early stage onwards.

Vennakkadan (2009) "mastery over spelling is a challenging task to achieve even in a considerably long span of time. Educational researchers continue to spend a good amount of time to evolve effective strategies to ensure reasonably good spelling skills in English but the truth is that still spelling in English evades the grip and grasp of many". The Spelling problems of language learners must be taken into account and addressed from early years of learning onwards because weak spelling skills hamper development of not only reading and writing skills but also convey a poor impression about the writer in spite of good contents or ideas.

Orton (1999) observes that there are explicit correlations between reading disabilities and spelling awareness of a child, and that development in one domain could have proportionate positive impacts on the other, and that neither domain should be neglected. Researches on reading skill have made it clear that spelling should not be given less importance but it can and should be an integral part of language curriculum and teaching for every student. It is further noted (Adams, 1990) that teaching spelling and handwriting provides a student who is weak in English with opportunities to use different senses and enhances his ability to gain mastery over the relationship between the phonemes and graphemes in a language, which plays a detrimental role in developing reading skill. Thus, the paper explores the necessity for a specific approach to spelling instruction in ELT curriculum, especially in TESL/TEFL context and illustrates the possibilities of integrating some innovative practices to teaching spelling. The potential pedagogic benefits and instructional efficacy of using the LFA tools in teaching/learning spellings are also dealt with.

\section{Need for a Specific Approach to Spelling}

A reflective look at the history of spelling instruction and the relatively sparse body of research done on the topic underscore the fact that teaching spelling and assigning due weight to it in assessment strategies were not a 
major concern in English language teaching or researching. Samuel Orton (1999) observed "an inability to spell is treated as of more or less minor importance" (p. 247) despite the fact that it is often associated with difficulties in reading. Tracing roots of the relative backseat for spelling instruction in the curriculum, Henderson and Templeton (1986) observe that teaching spelling was largely integrated into other macro skills and consequently it received little specific attention in instruction and testing practices. Templeton and Morris (2000) are of the view that paying a lukewarm attention to teaching spelling at schools deprives learners, especially those in the upper grades, of potentially important information about the orthographic system, which is detrimental to develop skills in reading and writing.

The pattern of English orthography is not a regular/certain phenomenon. Some words show tendency of solid regularity, some are pretty odd, and others are remarkably odd. The main reason for this intriguing irregularity is the lavish nature of English in loaning words from a variety of languages with which it had historical/political encounters. The fact that several languages has influenced English, specifically Anglo- Saxon, Norman French, Latin, and Greek etc and many linguistic peculiarities of these languages like spelling rules, organization of syllables, have been incorporated, also add to spelling oddities in English. Consequently, the spelling of a word is often related to, and even explained by, its history and language of origin. A close observation of English spelling system reveals the fact that it is at root alphabetic but with many exceptions to this principle (Chomsky, 1970). To large extend, the exceptions to the alphabetic nature are a result of representing 44 sounds (phones) in English using only 26 letters of the alphabet. Moreover, the English vocabulary which has diverse historical origins in other languages and the flexible nature of English in retaining/ adapting the non-native spellings of the borrowed words also account for the spelling abstraction. These factors, working in conjunction with the other, have made the English spelling system complicated, exemptions-ridden and a widely (dis)organized system. Therefore, it is imperative to pay due attention to spellings in ELT curriculum and methodology, especially in ESL/EFL context.

Vennakkadan (2010) observes that ability to read and ability to spell depends largely on the same underlying knowledge -the relationships between letters and sounds. Knowing the spelling of a word facilitates fluent and fast reading and better eye span. In writing, poor spellers are forced to limit themselves to words they can spell, with inevitable loss of verbal power, or while groping for the spelling of a word, they may lose track of their thoughts and end up in conveying the idea in a less impressive or ineffective way.

P. Hanna, Hodges, and J. Hanna (1971) are of the view that half of all English words can be spelled accurately on the basis of sound-symbol correspondences alone. Another 34 percent would only have one error if they were spelled on the basis of sound-symbol correspondences alone. They conclude that only four percent of words in English are really irregular.

It isn't logical to believe that the advent of computerized spell checkers/electronic gadgets has mitigated the relevance of spelling instruction because misspelling in any formal communication is still equated with poor command over writing skill and there's no evidence to believe that it will be overlooked in the years to come. In addition, electronic spell checkers often fail to discriminate between the use of homonyms in contexts and the efficient use of a spell checker also necessitates some reasonable skills in spelling.

To well orient learners to the complexities of the orthographic system in English in the early years of their English education, there must be adequate weight given to spelling in curriculum and instructional strategies. The disparity between the number of sounds in English and the insufficient number of letters for them to represent particularly worsens the spelling difficulties of English learners and the whole system entails further learning challenges when the L1 of the learners is markedly different from the sound symbol correlation of English.

\section{History of Spelling Instruction}

The perception that the English orthography is a broadly (dis)organized and unpredictable system has made its own impact on teaching and learning spelling right from the beginning (P. Hanna, Hodges, \& J. Hanna, 1971). The researchers on spelling instruction in the first half of the 20th century were largely influenced by this perception and their focus was on devising proper materials and methods to memorize spelling rules. They argued that the best way to teach spelling was by generalizing letter-sound rules, but studies held on the efficacy of this method showed it was ineffective (Yee, 1966). The incorporation of behaviorist principles in language learning stressed memorization of basic/frequent words through trial and error/drills. As a result, dictation and spelling tests were the main ways of teaching/learning spellings in ELT classrooms. Moreover, many basal spellers for various levels were made and they offered words to be learned without attention to orthographic principles. In essence, words were presented as separate units to be memorized one by one. Spelling instruction, 
at this time, was further dominated by the perception that students extensive exposure to reading and writing will enable them to master the spelling system naturally.

More recently, the paradigm underwent a shift as researchers stressed a strong need to have a focused approach to spelling (Zuttel, 2013). Though wider exposure and experience in reading and writing can have supportive and enriching influence on literacy learning, they alone are insufficient to attain good command over spelling skills. The three major approaches to spelling are phonemic, whole word and morphemic.

The phonemic approach emphasizes the need for orienting learners, especially in the early years, with the letter-sound correspondence. The exponents of this approach argue that many words in English have a one-to-one phonemic pattern and systematic instruction in phonemic patterns of high frequency words can not only boost students spelling skills but also escalate their reading skill development. The whole word approach, on the other hand, encourages grouping of words based on similarities or key identical factors and expects learners to use memorization strategy. It can be more effective for irregular words but spelling instruction could be dry and lacking interaction. Morphemic approach, unlike the other two, focuses on morphograms like prefix, suffix, root and the rules for combining them to generate different words/ spell whole words correctly. The numbers of morphemes, in relation to the vast vocabulary of English, is fewer and follows a predictable pattern in combination. Therefore, this approach is said to be highly effective and easy as it allows wider scope for student's participation and group work.

\section{Why LFA?}

Spelling instruction, if done in a traditional way of regurgitation and teacher centric method, will invite high degree of demotivation and poor learner involvement in ELT classes. The recent pedagogic principles stress the necessity of participatory learning and foregrounding learners from passive listeners to actively interactive learners by providing them with ample challenging tasks. The fact that English orthography is unpredictable can never be undone but the best way to fight this unpredictability is to make the whole teaching learning strategies in such a way that both learners and teachers find the process reasonably challenging, analytical, capitalizing on each other's higher order thinking skills and dexterous use of e-content/e-resources. If learners are involved in learning experiences that are intellectually compatible and innovatively appealing to their levels, drudgery becomes edutainment. Though it can't be as fun as a comic strip it can surely be more effective, challenging and participatory for learners.

The Learner Forefront Approach (LFA) to spelling is based on the concept that learning or acquiring knowledge and skills in given subject areas is best facilitated by involving more than one of learners' senses. It is further oriented in maximizing learner participation, individual pace and multi-level interaction with the help of tasks that necessitate learners to apply their thinking skills and schematic knowledge. This approach emphasizes the integrated use of auditory, visual, tactile and motor-kinesthetic cues for learning to track the correspondence between the sound patterns of oral language and the alphabetical patterns of written language. In LFA, spelling instruction is done using all learning pathways in the brain simultaneously in order to enhance memory and learning. Since it combines elements of visualization, pronunciation, peer tutoring and, e-resources and the positive sides of traditional spelling instruction, it is expected that LFA offers the optimum combination of instructional efficiency and effectiveness in learning/ teaching spelling. It turns the entire teaching process to an edutaining experience for learners and consequently the stress of misspelling in writing is really converted into ease of spelling mastery. The main LFA tools are the following.

\subsection{Segmentation}

In this tool, words that the learners find difficult or challenging to commit to memory are subject to a magical cutting so that each segment becomes a single/easily memorable unit. These segments are then linked with the schematic knowledge of learners to make the spelling get easily engraved in their minds. In short learners master the blending of sounds and letters into words as well as the segmenting of whole words into the individual sounds.

The first step in this method is to identify the problem area (PA) of the word and segment it to a meaningful/memorable unit using any improvised tactics that the instructor thinks suits the learners best. Studies have shown that the PA of most of the multisyllabic words in English pausing spelling confusion remains the same irrespective of minor differences in learners' background.

When properly integrated to instruction, this tool transforms the whole learning/teaching into learner-centered, interactive and effective process. To maximize learner centrality, the teacher may demonstrate one or two words 
and then leave the task of magical cutting to learners. I have experienced learners coming up with brighter ideas that I never thought of before or expected some of them will be able to associate with the word.

The advantage of this method is that the teacher can prepare a list of the difficult words of his/her students and ask them to segment in their own ways and discuss the best magical cut with the rest of the students in the class. It creates chances for intelligent learning, motivated and engraved memorization, learner participation and edutainment. A few examples of the magical cuts for some of the toughest spelling confusables are as follows. It would be both entertaining and cognitively challenging when a list of often misspelled words of your learners are handed over to them as an assignment to try out any of these tools with each word. A post assignment discussion in the class will be adding richer variety and greater innovation to wipe away the future spelling confusions related to words on the list.

$\begin{array}{ll}\text { Lieutenant } & : \text { lie } / \mathrm{u} / \text { ten } / \text { ant } \\ \text { Existence } & :(\mathrm{e}) \mathrm{x} / \text { is } / \text { ten } / \mathrm{c}(\text { see }) \text { or }(\mathrm{e}) \mathrm{x}=10 \\ \text { Privilege } & : \mathrm{i} / \mathrm{v} / \mathrm{i} / \mathrm{leg} / \text { or } \mathrm{i}=1(\text { figure }) \mathrm{v}=5, \mathrm{i}=1.151 \text { leg in privilege. } \\ \text { Assassination } & : \text { ass } / \text { ass } / \mathrm{i} / \text { nation }=2 \text { ass } \mathrm{i}(\text { eye }) \text { nation } \\ \text { Decease } & : \mathrm{d} / \mathrm{ec} / \text { ease } \text { or } \mathrm{ec}+\text { ease }=\text { decease double ease? } \\ \text { Weather } & : \text { we } / \text { at } / \text { her }\end{array}$

\subsection{Expansion}

This tool is dependent on expanding each letter of the problem area of a word in a memorable way or associating them with the general knowledge of learners. The spellings of words having wide discrepancy between phoneme and grapheme could easily be taught to learners with the help of this tool.

Like the previous tool, the word is first segmented. Then, the teacher /learner expands each segment in such a way that it helps learners memorize the spelling of the word with ease and accuracy. The process of expansion could be made strikingly clear and easy for quick grasp if it is done with the help of multimedia.

Some of the expansions I successfully experimented with my learners or I modified integrating ideas borrowed from my students were the following. Don't you feel the problem area in many words (a few given) will easily be washed off for good if you expand the words in this manner? Although it is not a full stop to their spelling headaches, it can help change the way they learn spelling and modify their attitude to English orthography.

Restaurant

Manoeuvre

Accommodation

Truly

Because
: rest/after/u/ran

: no/e/u/v/r/e expanded no ever $\mathrm{u}(\mathrm{you})$ and $\mathrm{v}(\mathrm{we}) \mathrm{r}$ (are) enemies

: the problem area ccommo is expanded as double C? Of course \& double M? Of course.

: T/R/U/ly expanded Tom, r(are) u(you) lying, truly?

: use $\mathrm{A}$ after $\mathrm{C}$ in because

\subsection{Picturisation}

It is very interesting to note that many words in English have certain images hidden/implied in it. In this method, the teacher helps learner get over the problem of spelling difficulty unveiling the images of close familiarity in the problem area(s) and shows them either in the background or instead of the letters it stands for. This tactic could best be done and made most effective with the use of multi-media teaching aids in the classroom.

This method promotes the imaginative abilities of the learners. If a list of often misspelled words is given as homework the learners could work at their own pace and add variety and color to learning spelling. 


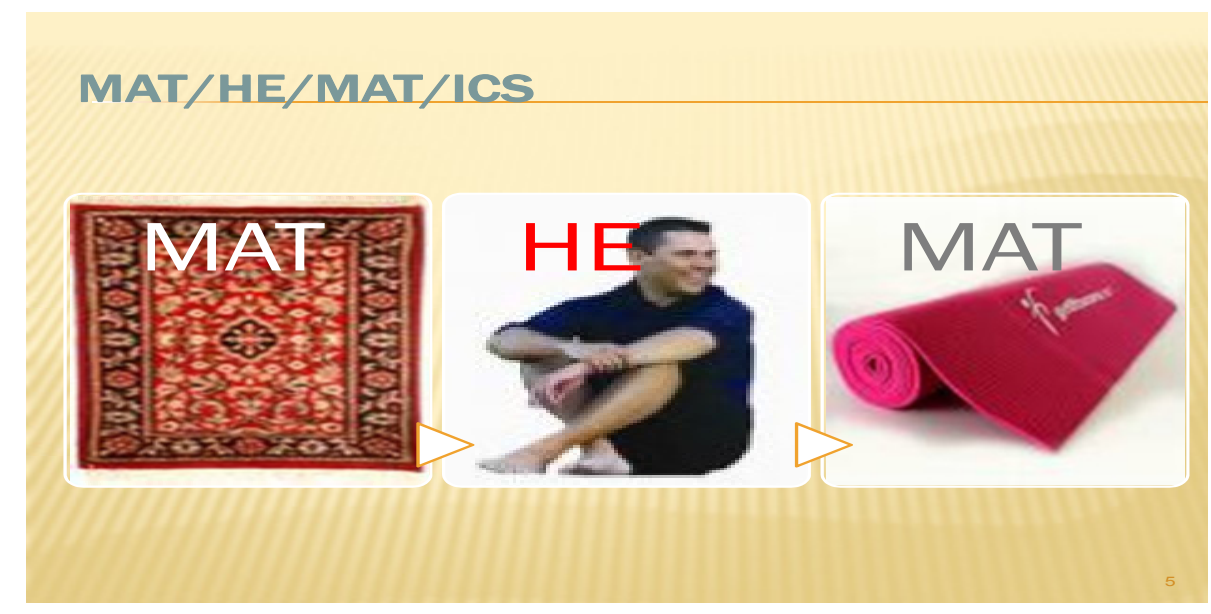

Figure 1. MAT/HE/MAT $=$ HE is sitting between MAT and MAT

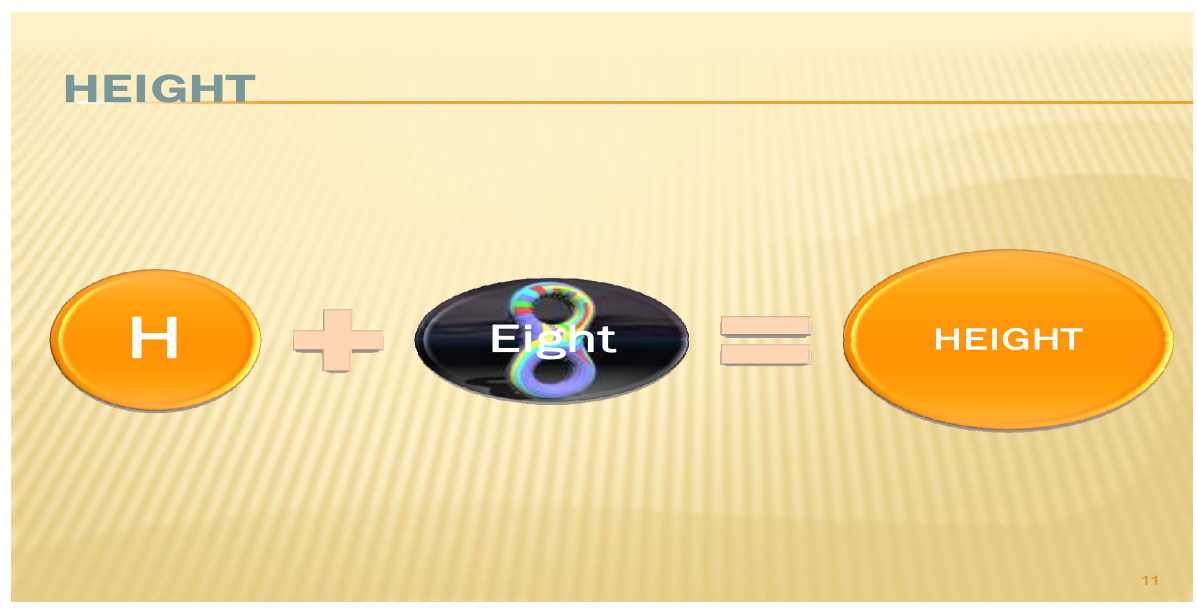

Figure 2. HEIGHT $=\mathrm{H}+8$ (eight)

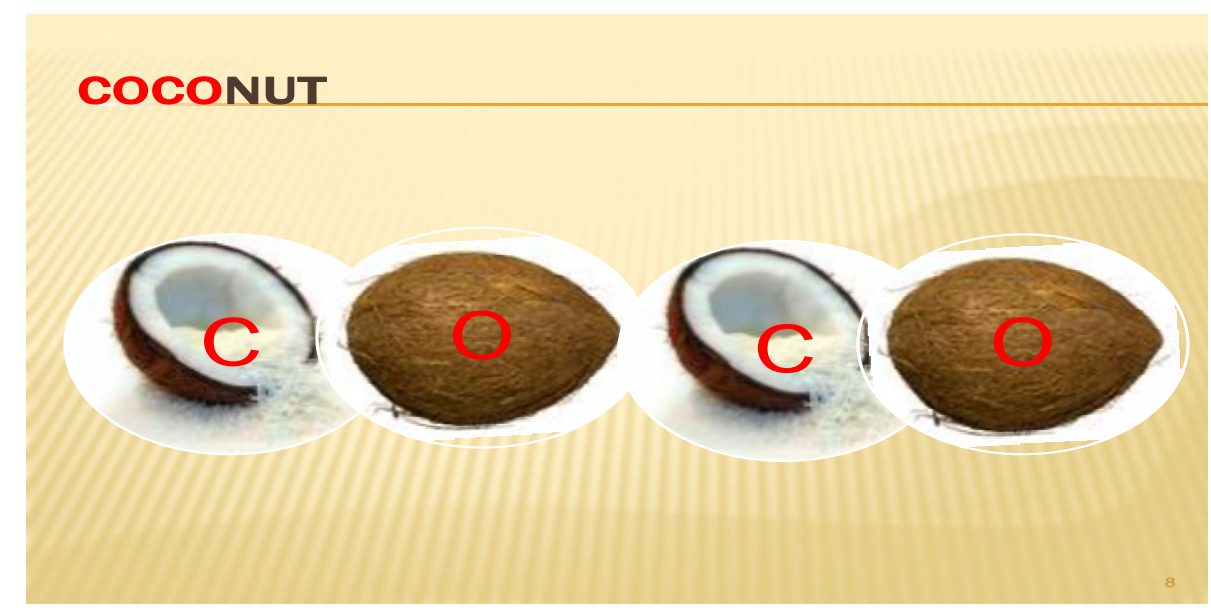

Figure 3. COCONUT $=($ half $)+($ full $)+($ half $)+($ full $)$

\subsection{Spellfilter}

My experience as an EFL instructor has made it clear that English teachers/students irrespective of their level of education/qualification continue to be troubled by the question of what to choose between $\mathrm{E} / \mathrm{I}$ in a long list of EI/IE WORDS in English. The irregular occurrence of I/E in these words makes it impossible to bind them with 
a single rule. One of the conventional spelling rules that we make our students memorize is that the letter " $\mathrm{C}$ " is always followed by " $E$ " not "I" but on analysis the rule proves to have exceptions because we have words like efficient, sufficient where the following letter is "I".

Spellfilter is a way of solving EI/IE confusables with a mathematical precision and accuracy. It is a practical/practicable way of learning spelling where learners learn by doing not by rote memorization or generalization. It offers an almost full solution to this confusion in a simple manner. Words in which EI/IE stands for the sound /i:/, /i/ can easily be filtered with this without having any grain of doubt creeping again.

The spellfilter has got two parts namely A-part and Z-part and the direction of the movement in these two (as shown by the arrows) are forward and backward respectively. The Focal Letter (FL) on the scale stands for the letter that precedes I/E and the Target Letter (TL) means the letter to be used after FL. The three steps to filter EI/IE WORDS are as follows.

Table 1. Spellfilter

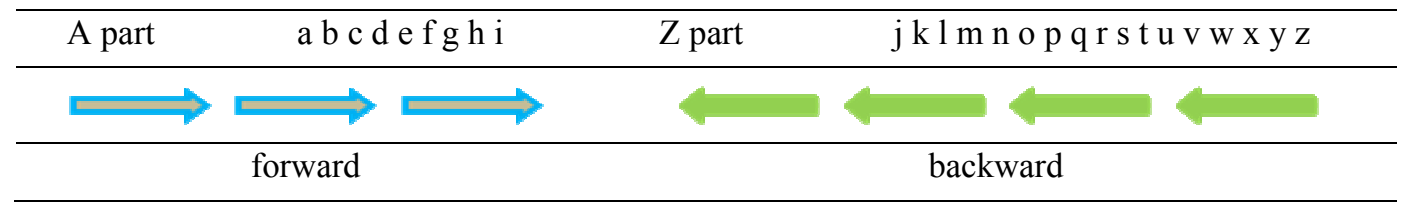

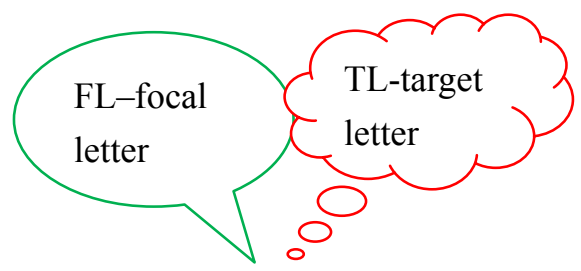

RECEIVE

3 steps

1) Locate the FL

2) Identify the part of the FL (A or B)

3) Move forward/backward to fix TL

For example the word shield has " $h$ " as its FL and it falls in A-PART on the spellfilter in which the direction of the movement is always forward. As you move ahead you get the TL which is "I" and when you come backward you get the second TL which is " $E$ ". Thus your doubt of what to choose after $\mathrm{I} / \mathrm{E}$ is easily wiped out.

Table 2. Achieve

\begin{tabular}{|c|c|c|c|}
\hline A part & abcdefghi & Z part & jklmnopqrstuvw $x y z$ \\
\hline \multicolumn{4}{|c|}{$\mathrm{h}(\mathrm{FL}) \longrightarrow \mathrm{i}(\mathrm{TL})$} \\
\hline & ward & & backward \\
\hline
\end{tabular}

Table 3. Besiege

\begin{tabular}{|c|c|c|c|}
\hline A part & $a b c d e f g h i$ & Z part & jklmnopqrstuvw xyz \\
\hline \multicolumn{4}{|c|}{$\mathrm{i}(\mathrm{TL}) \longleftarrow(\mathrm{FL}) \mathrm{s}$} \\
\hline & forward & & backward \\
\hline
\end{tabular}

Almost all words in which IE/EI combination occurs could easily and accurately be filtered on this scale. The notion perfection itself is imperfect and in a similar way there are a very few words in English standing outside spellfilter to underline the truth that English orthography is reasonably complex and irregular. 
The spellfilter works on the basis of the sounds of FL and TL because in words like efficient and sufficient the Focal Letter " $C$ " has the sound $/ S /$ which falls in Z-part not in A-part. So the first Target Letter of " $C$ " in these words is "I" and the second TL is "E". When the IE/EI combination stands for the sound /ei/ as in neighbor or freight etc the spellfilter does not work but it is applicable, more than $99 \%$, when EI/IE combination represents the phoneme /i:/.

Inclusions:

Receive, conceive, achieve, ceiling, field, sieve, grief, efficient, friend, patience, view, fierce, believe, relief, client, shield, retrieve, piece, grief, yield, thief, priest etc.

Exclusions:

Seize, diesel, neither, neighbor.

4.5 Spellwares

Spellwares are softwares meant for teaching or learning spellings. There are a good number of spellwares both free and paid which could be downloaded from the internet. The constructive use of the possibilities of technology in these programs replaces the drudgery of rote memorization of spelling rules with interactive as well as exciting practices on the part of the learners.

They have the added merits of self pace, learner centeredness, greater motivation and quick feedback. It allows learners to create, record, sort, and save a spelling list so that they can practice each day for a spelling test. There is provision to review reports of their grades and misspelled words. The following are some of the sites offering free/paid spellwares.

http://www.ispellwell.com

http://www.spellingtime.com

http://www.spellingcity.com

http://www.tis-co.com

http://www.spellingmadesimple.com

http://www.bigiqkids.com/SpellingTest/FreeSpellingProgram.html

$\mathrm{http}: / /$ www.spellquizzer.com

http://www.helpyouspell.com

\section{Conclusion}

Cornnel (1978) writes misspelling marks a person as, at least, illiterate, if not outright, ignorant (p. 202). The quote accentuates the significance of spelling in written English and general attitude towards misspelling. As spelling is crucial for reading comprehension and writing skill, due weight to spelling mastery and a specific approach to spelling instruction must be a concern in ELT curriculum and methodology at school and university levels. Though LFA to spelling instruction is not a panacea for ensuring a commanding grip over the intriguing and elusive English orthography, it can considerably transform the process of learning and teaching spelling skills in a constructive and learner active way. It has shown mitigating the difficulty level of both the teacher's and learner's while learning and teaching spelling and has left productive space, in a greater degree, for learner autonomy, interaction, group work and higher order thinking skills in TESLTEFL context than a traditional mode of spelling instruction succeeds to achieve.

\section{References}

Adams, M. J. (1990). Beginning to read: Thinking and learning about print. Cambridge, MA: MIT Press.

Chomsky, C. (1970). Reading, writing, and phonology. Harvard Educational Review, 40, 287-309.

Cronnell, B. (1978). Spelling English as a Second Language. In M. C. Muria, \& M. L. M. Rowley (Eds.), Teaching English as a Second or Foreign Language. Newbury House.

Michael, F. (2008). Spelling knowledge and reading development: Insights from Arab ESL learners. Reading in a foreign language, 20, 19-42.

Hanna, P. R., Hodges, R. E., \& Hanna, J. S. (1971). Spelling: Structure and strategies. Boston: Houghton Mifflin.

Henderson, E., \& Templeton, S. (1986). A developmental perspective of formal spelling instruction through 
alphabet, pattern, and meaning. The Elementary School Journal, 86, 305-316.

Orton, S. T. (1999). Reading, writing, and speech problems in children, and selected papers. Baltimore, MD: International Dyslexia Association.

Templeton, S., \& Morris, D. (2000). Spelling. In M. L. Kamil, P. B. Mosenthal, P. D. Pearson, \& R. Barr (Eds.), Handbook of reading research (Vol. 3, pp. 525-543). Mahwah, NJ: Lawrence Erlbaum Associates.

Vennakkadan, L. (2012) Spelling Mastery through the Internet and E-learning. Language in India, 12(5), 92-97. Retrieved March 8, 2013, from http://www.languageinindia.com/may2012/latheefspellingmastery.html

Vennakkadan, L. (2009, April). Spelltics-A Multisensory Approach. Abstract presented at the $6^{\text {th }}$ Oman International ELT conference, Sultan Qaboos University (SQU) Muscat, Oman. Retrieved October 20, 2010, from http://web.squ.edu.om/lan/Conference\%202009/Handouts/Abdullateef.pdf

Yee, A. H. (1966). The generalization controversy on spelling instruction. Elementary English, 43, 154-161.

Zuttel, J. (2013). Student-Active Learning Approach to Spelling Instruction. Retrieved April 20, 2014, from http://www.zaner-bloser.com/news/student-active-learning-approach-spelling-instruction

\section{Copyrights}

Copyright for this article is retained by the author(s), with first publication rights granted to the journal.

This is an open-access article distributed under the terms and conditions of the Creative Commons Attribution license (http://creativecommons.org/licenses/by/3.0/). 